Article

\title{
Biological Maturity Status, Anthropometric Percentiles, and Core Flexion to Extension Strength Ratio as Possible Traumatic and Overuse Injury Risk Factors in Youth Alpine Ski Racers: A Four-Year Prospective Study
}

\author{
Lisa Steidl-Müller ${ }^{1, *}$, Carolin Hildebrandt ${ }^{1}$, Martin Niedermeier ${ }^{1}{ }^{\mathbb{D}}$, Erich Müller ${ }^{2}$ (D), \\ Michael Romann ${ }^{3}$ (D), Marie Javet ${ }^{3}$, Björn Bruhin ${ }^{3}$ and Christian Raschner ${ }^{1}$ \\ 1 Department of Sport Science, University of Innsbruck, 6020 Innsbruck, Austria; \\ carolin.hildebrandt@uibk.ac.at (C.H.); martin.niedermeier@uibk.ac.at (M.N.); \\ christian.raschner@uibk.ac.at (C.R.) \\ 2 Department of Sport and Exercise Science, University of Salzburg, 5020 Salzburg, Austria; \\ erich.mueller@sbg.ac.at \\ 3 Section for Elite Sport, Swiss Federal Institute of Sport Magglingen, 2532 Magglingen, Switzerland; \\ Michael.romann@baspo.admin.ch (M.R.); marie.javet@baspo.admin.ch (M.J.); \\ bjoern.bruhin@baspo.admin.ch (B.B.) \\ * Correspondence: lisa.steidl-mueller@uibk.ac.at; Tel.: +43-(0)512-507-45904
}

Received: 30 September 2020; Accepted: 27 October 2020; Published: 29 October 2020

\begin{abstract}
The aim of the present study was to investigate prospectively the role of biological maturity status, anthropometric percentiles, and core flexion to extension strength ratios in the context of traumatic and overuse injury risk identification in youth ski racing. In this study, 72 elite youth ski racers (45 males, 27 females) were prospectively observed from the age of 10 to 14 years. Anthropometric parameters, biological maturity status, and core flexion to extension strength ratios were assessed twice per year. Type and severity of traumatic and overuse injuries were prospectively recorded during the 4 years. Generalized estimating equations were used to model the binary outcome (0: no injury; $1: \geq 1$ injury). Factors tested on association with injury risk were sex, relative age quarter, age, maturity group, puberty status, core flexion to extension strength ratio, height percentile group, and weight percentile group. In total, 104 traumatic injuries and 39 overuse injuries were recorded. Age (odds ratio $(\mathrm{OR})=3.36$ ) and weight percentile group $(\mathrm{OR}=0.38$ ) were significant risk factors for traumatic injuries (tendency: pubertal status). No significant risk factor for overuse injuries was identified (tendency: maturity group, puberty status, height percentile group). Future studies should focus on identifying risk factors for overuse injuries; growth rates might be of importance.
\end{abstract}

Keywords: youth ski racing; injury risk; biological maturity; anthropometric characteristics; core flexion to extension strength ratio; talent development

\section{Introduction}

Sport specialization in the immature athlete has profound effects on short- and long-term injury risks and joint health [1]. Even though alpine ski racing is a late specialization sport and the peak performance in elite alpine ski racing is achieved between the ages of 26 (females) and 28 years (males), youth ski racers at the ages of 10 to 14 years already have high weekly volumes of skiing-specific (734.0 $\pm 232.7 \mathrm{~min})$ and additionally athletic-specific training (201.1 $\pm 122.0 \mathrm{~min})$ [2]. High training volumes at an early age combined with an athlete's long competitive life needs to be considered 
when implementing strategies to develop talents. In this context, a large number of specialized ski boarding schools for talented young athletes provide a fundamental basis for a future professional career. Research has shown that training load parameters did not represent injury risk factors in young ski racers [2], which is a result that emphasizes the importance of such well-planned training structures for young athletes.

Nevertheless, alpine ski racing is a sport with a high risk of injury in elite athletes at World Cup and European Cup levels [3] but also at youth (10-14 years) [4] and adolescent levels (15-19 years) [5]. At the youth level, traumatic injury rates of 0.63 /athlete per season, as well as overuse injury rates of 0.21 /athlete per season were reported [4]. The knee was the most affected body part by both traumatic (36.5\% of all traumatic injuries) and overuse injuries ( $82.3 \%$ of all overuse injuries). Up to now, studies prospectively investigating injury risk factors in youth ski racing were conducted only for one to two seasons [4,6-8]. Due to the short observation period, the small sample sizes because of the general small cohort of elite athletes in this age group, and the consequently small numbers of traumatic and overuse injuries, risk factors were usually identified for both traumatic and overuse injuries combined. However, due to the growing back overuse problems in alpine ski racing, it seems important to identify risk factors separately for traumatic and overuse injuries, respectively.

Growth-related factors such as biological immaturity contribute to overuse injuries [9]. The risk of sustaining overuse injuries is strongly intensified during the adolescent growth spurt [10]. Late maturing soccer players were at a higher risk for both overuse injuries [11] and severe traumatic injuries [12]. Additionally, late maturing youth ski racers were more vulnerable for more severe injuries (traumatic and overuse injuries combined) [4]. In this context, it seems important to prospectively assess youth athletes over a longer period during their pubertal years to better understand the role of biological maturity as a possible risk factor for both traumatic and overuse injuries. Additionally, further variables based on previous research might be considered in injury risk analyses. Firstly, anthropometric percentiles might be worth consideration for identifying possible risk factors among youth ski racers aged 10 to 14 years. Secondly, core strength was found to be a significant risk factor for injuries in youth ski racers [4], and for ruptures of the anterior cruciate ligament (ACL) in adolescent athletes [13]; in adolescent ski racers, core strength imbalances were significant risk factors for ACL injuries in male athletes [13]; however, core flexion to extension strength ratios have not yet been considered in injury risk identification in youth ski racers. Therefore, the aim of the present study was to investigate prospectively over a period of 4 seasons the role of biological maturity status, body weight, and body height percentiles and core flexion to extension strength ratios in the context of traumatic and overuse injury risk identification in elite youth ski racers from the ages of 10 years at the beginning of the observation period.

\section{Materials and Methods}

\subsection{Study Design}

The Institutional Review Board of the Department of Sport Science of the University of Innsbruck and the Board for Ethical Questions of the University of Innsbruck approved the study (\#02/2014). A four-season prospective longitudinal study design was used to record traumatic and overuse injuries as well as anthropometric parameters, biological maturity status, and core flexion to extension strength ratios in a cohort of elite youth ski racers aged 10 years at the beginning of the study (until 14 years of age). All tests were performed in the laboratory of the Department of Sport Science, University of Innsbruck, by experienced researchers, at the same time of day (3 p.m.) and under standardized laboratory conditions (standardized shoes of the laboratory, same order of tests etc.) and using the same measurement systems to ensure repeatability and to limit confounding influences. The diverse parameters were tested twice per year: prior to the start of the competitive season (end of September) and at the end of the winter season prior to the preparation season (end of April). Traumatic and overuse injuries were recorded prospectively during the four years. 


\subsection{Participants}

In total, 72 elite youth ski racers (45 males, 27 females), who were pupils of a very famous ski boarding school and who all competed at national levels in Austria, were included in the study. The athletes represent a cohort of very successful elite youth ski racers. No power calculations were performed, as all available pupils were included in the study. Inclusion criteria were as follows: (a) school attendance at the start of the study, including a medical screening (e.g., for musculoskeletal, circulatory, or neurological disorders) when entering the boarding school, (b) being free of acute injuries at the start of the study, and (c) being free of relevant chronic diseases. The pupils were prospectively observed and investigated from the age of approximately 10 years until the age of approximately 14 years, as they frequented the skiing-specific secondary modern school for 10- to 14-year-olds. At the start of the study, the mean age of the pupils was $10.6 \pm 0.3$ years. The mean weekly training volume of skiing-specific training was $727.3 \pm 143.4 \mathrm{~min}$, and the mean weekly training volume of athletic-specific training was $211.6 \pm 76.2 \mathrm{~min}$. The athletes participated in an average of $16.7 \pm 9.2$ races/season. The anthropometric characteristics of male and female athletes at the beginning of the study are presented in Table 1 . All athletes, their parents, and coaches were informed about the study aims, risks, and benefits, and the parents of the athletes provided their written informed consent.

Table 1. Anthropometric characteristics of male and female athletes at the start of the study.

\begin{tabular}{ccc}
\hline \multirow{2}{*}{ Anthropometric Characteristics } & \multicolumn{2}{c}{ Sex } \\
\cline { 2 - 3 } & Male & Female \\
\cline { 2 - 3 } & $\mathbf{M} \pm$ SD & M \pm SD \\
\hline Age [yrs] & $10.6 \pm 0.4$ & $10.5 \pm 0.3$ \\
Height [cm] & $144.6 \pm 5.5$ & $142.5 \pm 6.0$ \\
Weight $[\mathrm{kg}]^{2}$ & $35.3 \pm 5.1$ & $34.0 \pm 4.9$ \\
BMI $^{1}\left[\mathrm{~kg} / \mathrm{m}^{2}\right]$ & $16.8 \pm 1.9$ & $16.7 \pm 1.7$ \\
Sitting height $[\mathrm{cm}]^{\text {APHV }}{ }^{2}[\mathrm{yrs}]$ & $77.5 \pm 4.3$ & $77.7 \pm 4.6$ \\
A & $13.5 \pm 0.4$ & $12.0 \pm 0.4$ \\
\hline
\end{tabular}

${ }^{1}$ BMI: body mass index; ${ }^{2}$ APHV: age at peak height velocity.

\subsection{Data Collection}

\subsubsection{Anthropometric Parameters and Biological Maturity Status}

The anthropometric characteristics of body height $(0.5 \mathrm{~cm}$; portable Stadiometer SECA 217; SECA, Hamburg, Germany), body weight (1N, Kistler force plate; Kistler Instrumente AG, Winterthur, Switzerland; calculated to the nearest $0.1 \mathrm{~kg})$, and sitting height $(0.5 \mathrm{~cm}$; portable Stadiometer SECA 217; SECA, Hamburg, Germany; sitting height table) were assessed. Additionally, the leg length as difference between body height and sitting height $(0.5 \mathrm{~cm})$ and the body mass index (BMI; $\left.0.1 \mathrm{~kg} / \mathrm{m}^{2}\right)$ were calculated. The percentiles of body height and body weight were classified according to Braegger et al. [14]. Percentiles of body height and body weight were categorized in three groups (0: percentile 25 and below; 1 : between percentile 25 and $<75$; 2: percentile 75 and above), which was done in accordance with Kromeyer-Hauschild et al. [15].

The biological maturity status was assessed using the non-invasive method of calculating the age at peak height velocity (APHV) [16]. These sex-specific prediction equations include the aforementioned anthropometric characteristics (except for BMI) as well as the calculated actual chronological age at the time of measurement. Then, based on these values, the maturity offset as the time before or after individual peak height velocity (PHV) was calculated. Then, the difference between the actual chronological age and the maturity offset was defined as APHV. Then, participants were categorized into three maturity groups according to the sex-specific APHV of the present sample [17,18]: early maturing, defined as APHV below sex-specific mean - standard deviation; normal maturing, defined as sex-specific mean APHV \pm standard deviation; and late maturing: APHV higher than sex-specific mean + standard deviation. A negative maturity offset indicated that the athlete was pre PHV, whereas a 
positive maturity offset indicated post PHV [16]. In accordance with Faigenbaum et al. [19] and Lesinski et al. [20], puberty status was classified as pre-pubertal: maturity offset -1 and smaller; pubertal: maturity offset between -1 and 1 ; and post-pubertal: maturity offset 1 and larger. A previous study [18] confirmed the validity of this APHV method for 10- to 13-year-old youth ski racers. The difference between the calculated APHV and the actual age at the day of the occurrence of an injury was defined as maturity offset at time of injury occurrence. The birth months of the athletes were split into relative age quarters; relative age quarter 1 (Q1) included the birth months January, February, and March; Q2 included April, May, and June; Q3 included July, August, and September; and Q4 included October, November, and December.

\subsubsection{Core Flexion to Extension Strength Ratio}

The core flexion and extension strength test is part of the test battery for junior ski athletes as described by Raschner et al. [21], which was established in consultation with sports scientists, ski racing experts, and coaches. The maximal isometric core flexion and extension strength were measured using the slightly modified Back-Check (Dr. Wolff Sports \& Prevention GmbH, Arnsberg, Germany). The athlete was in an upright standing position, with knees slightly flexed and pelvis stabilized; pads, which were connected to a force transducer, were set at sternum level (anteriorly and posteriorly). Against these cushioned pads, the athlete contracted maximally. The athletes conducted three trials each (flexion and extension), and the highest force of the three attempts each were recorded [21]. Then, the ratio of flexion to extension strength was calculated by dividing the flexion strength by the extension strength. The test-retest reliability analysis among high-level athletes identified intra class correlation coefficients (ICCs) of 0.77 (flexion) and 0.90 (extension) [22]. Subsequently, the ratio of core flexion to extension strength was categorized to 0 for a ratio $\leq 1$ indicating higher strength in extensors or equal strength; and to 1 for a ratio $>1$ indicating higher strength in flexors.

\subsubsection{Injury Registration}

A sport-specific internet-based database was developed and used in the present study; a detailed description of the database was reported by Müller et al. [4]. Using this database, coaches of the ski boarding school recorded all relevant training data immediately after each skiing-specific and athletic training session. In case of absence of an athlete due to traumatic injury or overuse injury, a member of the study team contacted the coaches, physiotherapists, and/or physicians of the ski boarding school to get detailed information. Based on the information, all traumatic and overuse injuries that caused absence from training for at least one day were then registered by the member of the study team using the internet-based database. A detailed medical report was provided in case of an injury that required medical attention. The date of injury, the severity of injury, the circumstance of the injury, the affected body part, the type of injury were recorded, among other factors.

A traumatic injury was defined as an injury with a sudden onset based on time-loss definition [23]. Based on the injury surveillance consensus paper of the International Olympic Committee [24], the type of traumatic injury and the affected body part were defined. The injury severity was defined according to Fuller et al. [25]: An injury was classified as minimal with a time-loss of 1-3 days, extending to mild (4-7 days), moderate (8-28 days), severe ( $>28$ days), or career ending. Based on the definition by Clarsen et al. [26], an overuse injury was defined as any physical complaint without a single identifiable event being responsible.

\subsection{Statistical Analyses}

Statistical analyses were done using SPSS v. 26 (IBM, New York, NY, USA). Risk factors for traumatic and overuse injuries were analyzed separately. The eight test time points resulted in repeated measurements (up to eight) in the athletes. Ordinary binary regression analysis is expected to produce biased estimates of the regression analysis. Therefore, generalized estimating equations (GEE) were used to model the binary outcome in which 0 represents no injury, and 1 represents at least one 
injury. GEE was preferred compared to ordinary binary regression analysis since GEE accounts for the inter-correlation of repeated observations in the same subjects over time and was used in the injury context previously [27]. A working correlation matrix with exchangeable structures was used. The first step of the primary statistical analysis consisted of a series of simple GEE models using all potential associated factors separately. In detail, the factors tested on association with injury risk were sex, relative age quarter, age, maturity group, puberty status, core flexion to extension strength ratio group, height percentile group, and weight percentile group. The odds ratio (OR) including $95 \%$ confidence intervals $(95 \% \mathrm{CI})$ was calculated for each factor. In a second step of the primary statistical analyses, a multiple GEE model with all significant associated factors in the simple analysis was conducted. Quasi-information criterion (QIC) was given for the multiple GEE model. A lower QIC value indicates a better model fit [28].

As an additional analysis, a series of multiple binary regression analyses with stepwise backward elimination was performed separately for each test time point. The regression analysis is regarded as secondary and as a supplement to the GEE, since it cannot consider repeated observations across athletes. $p$-values $<0.05$ were considered as significant and $p$-values ranging from 0.05 to 0.10 were considered as tendencies.

\section{Results}

\subsection{Injury Chracteristics}

In total, $n=482$ observations from 72 ski racers were available with 104 traumatic injuries (45 separate athletes) and 39 overuse injuries (25 separate athletes). Average injury incidence across all time points was 0.22 injuries/athlete for traumatic and 0.08 injuries/athlete for overuse injuries (Figure 1 ). Most traumatic injuries were moderate $(41.3 \%)$, followed by mild $(23.1 \%)$, minimal $(20.2 \%)$, and severe (15.4\%). Most overuse injuries were mild (33.3\%), followed by moderate (30.6\%), minimal $(22.2 \%)$, and severe $(13.9 \%)$. None of the injuries was career ending. The predominant injury location of traumatic injuries was in the lower extremities ( $66.3 \%$ of all injuries), followed by upper extremities $(19.2 \%)$, trunk (8.7\%), and head (5.8\%). Among the traumatic injuries located at the lower extremities, $44.7 \%$ were moderate injuries, and $18.4 \%$ were minimal, mild and severe injuries each. Overuse injuries were located in the lower extremities $(82.4 \%)$ or in the trunk $(17.6 \%)$. Among the overuse injuries located at the lower extremities, most of them were classified as moderate injuries (34.4\%), followed by mild $(31.3 \%)$, minimal $(21.8 \%)$ and severe (12.5\%). Twenty-two athletes had a traumatic (eight athletes had an overuse) injury on more than one observation. In 15 observations, more than one traumatic injury was found, resulting in 87 observations with at least one traumatic injury. In two observations, more than one overuse injury was found, resulting in 36 observations with at least one overuse injury.

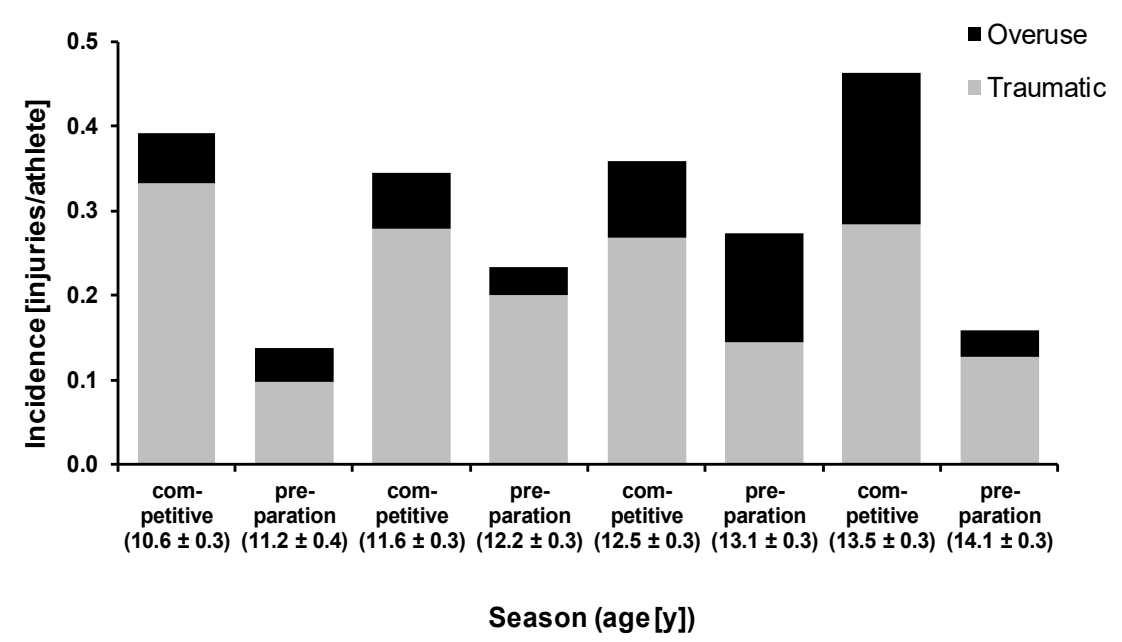

Figure 1. Incidence of traumatic (gray) and overuse (black) injuries per athlete by test time point. 


\subsection{Factors Associated with Traumatic Injuries}

Out of all factors tested on association with traumatic injuries using simple GEE analysis, age and weight percentile group were significant (Table 2). Compared to the age of 14 years, being 10 years old was associated with a significantly higher risk for traumatic injury $(\mathrm{OR}=3.36)$. Compared to being in the weight percentile of 75 and above, being in the weight percentile 25 and below was associated with a significantly lower risk for traumatic injury $(\mathrm{OR}=0.38)$. Puberty status showed a tendency for a higher injury risk for pre-pubertal athletes compared to post-pubertal athletes. The other potential factors including sex, relative age variables, core flexion to extension strength ratio, and height were non-significant.

Table 2. Potential factors associated with traumatic injuries according to the simple general estimating equation analysis ( $n=482$ observations).

\begin{tabular}{|c|c|c|c|c|c|c|c|}
\hline Variable & $\begin{array}{l}\% \text { Observations } \\
\text { with Injuries }\end{array}$ & $\begin{array}{l}\text { N Observations } \\
\text { with Injuries }\end{array}$ & N Observations & $p$ & $\mathrm{OR}^{1}$ & $95 \%$ CI lb ${ }^{2}$ & $95 \% \mathrm{CI}_{\mathrm{ub}}{ }^{3}$ \\
\hline \multicolumn{8}{|l|}{ Sex } \\
\hline Female & $16.2 \%$ & 31 & 191 & 0.655 & 0.86 & 0.43 & 1.69 \\
\hline Male & $19.2 \%$ & 56 & 291 & & 1 (ref) & & \\
\hline \multicolumn{8}{|c|}{ Relative age quarter } \\
\hline 1st & $15.7 \%$ & 24 & 153 & 0.692 & 0.79 & 0.25 & 2.52 \\
\hline 2nd & $20.1 \%$ & 30 & 149 & 0.873 & 1.10 & 0.34 & 3.51 \\
\hline $3 \mathrm{rd}$ & $19.2 \%$ & 20 & 104 & 0.965 & 1.03 & 0.29 & 3.63 \\
\hline 4 th & $17.1 \%$ & 13 & 76 & & 1 (ref) & & \\
\hline \multicolumn{8}{|l|}{$\begin{array}{c}\text { Age } \\
\text { [years] }\end{array}$} \\
\hline 10 & $28.1 \%$ & 16 & 57 & 0.021 & 3.63 & 1.22 & 10.81 \\
\hline 11 & $17.4 \%$ & 19 & 109 & 0.174 & 2.06 & 0.73 & 5.86 \\
\hline 12 & $20.0 \%$ & 26 & 130 & 0.080 & 2.46 & 0.90 & 6.73 \\
\hline 13 & $15.6 \%$ & 21 & 135 & 0.213 & 1.88 & 0.70 & 5.09 \\
\hline 14 & $9.8 \%$ & 5 & 51 & & 1 (ref) & & \\
\hline \multicolumn{8}{|c|}{ Maturity group ${ }^{4}$} \\
\hline Early & $19.7 \%$ & 15 & 76 & 0.670 & 1.26 & 0.43 & 3.73 \\
\hline Average & $18.2 \%$ & 60 & 330 & 0.739 & 1.16 & 0.48 & 2.78 \\
\hline Late & $15.8 \%$ & 12 & 76 & & 1 (ref) & & \\
\hline \multicolumn{8}{|l|}{$\begin{array}{l}\text { Puberty } \\
\text { status } 5\end{array}$} \\
\hline Pre-pubertal & $21.8 \%$ & 39 & 179 & 0.073 & 1.86 & 0.94 & 3.67 \\
\hline Pubertal & $16.7 \%$ & 37 & 222 & 0.348 & 1.36 & 0.71 & 2.61 \\
\hline Post-pubertal & $13.6 \%$ & 11 & 81 & & 1 (ref) & & \\
\hline \multicolumn{8}{|c|}{ Core flexion to extension strength ratio group ${ }^{6}$} \\
\hline $\begin{array}{c}\text { Ratio } 1 \\
\text { and below }\end{array}$ & $16.1 \%$ & 38 & 236 & 0.287 & 0.76 & 0.45 & 1.26 \\
\hline Ratio $>1$ & $19.5 \%$ & 41 & 210 & & 1 (ref) & & \\
\hline \multicolumn{8}{|c|}{ Height percentile group ${ }^{7}$} \\
\hline $\begin{array}{l}25 \text { and } \\
\text { below }\end{array}$ & $17.2 \%$ & 20 & 116 & 0.403 & 0.68 & 0.27 & 1.70 \\
\hline$>25$ to $<75$ & $17.3 \%$ & 51 & 295 & 0.401 & 0.72 & 0.34 & 1.54 \\
\hline $\begin{array}{l}75 \text { and } \\
\text { above }\end{array}$ & $23.4 \%$ & 15 & 64 & & 1 (ref) & & \\
\hline \multicolumn{8}{|c|}{ Weight percentile group 8} \\
\hline $\begin{array}{l}25 \text { and } \\
\text { below }\end{array}$ & $11.0 \%$ & 13 & 118 & 0.034 & 0.38 & 0.15 & 0.93 \\
\hline$>25$ to $<75$ & $18.9 \%$ & 54 & 286 & 0.333 & 0.69 & 0.32 & 1.47 \\
\hline $\begin{array}{l}75 \text { and } \\
\text { above }\end{array}$ & $25.7 \%$ & 18 & 70 & & 1 (ref) & & \\
\hline
\end{tabular}

${ }^{1}$ OR: odds ratio, ${ }^{2}$ 95\%CI lb: 95\% confidence interval lower bound, ${ }^{3}$ 95\%CI ub: 95\% confidence interval upper bound, ${ }^{4}$ groups according to age at peak height velocity, ${ }^{5}$ according to distance to age at peak height velocity, ${ }^{6}$ missing observations $=36,{ }^{7}$ missing observations $=7,8$ missing observations $=8$, bold values indicate statistically significant values.

According to the multiple GEE analysis, both age and weight percentile group remained significantly associated with traumatic injury risk (Table 3), QIC $=446.9$. Adding the variable puberty status did not improve the model according to the QIC $=449.7$. According to the series of multiple linear regression analysis with stepwise backward elimination, the weight percentile group 
was the only remaining significant factor at time points 3 and 4 . No significant factors remained for the other time points.

Table 3. Results of the multiple general estimating equation analysis of factors associated with traumatic injuries based on $n=474$ observations.

\begin{tabular}{|c|c|c|c|c|c|}
\hline Variable & $\%$ Observations with Injuries & $p$ & OR $^{1}$ & $95 \% \mathrm{CI} \mathrm{lb}^{2}$ & $95 \% \mathrm{CI} \mathrm{ub}^{3}$ \\
\hline \multicolumn{6}{|l|}{ Age [years] } \\
\hline 10 & $28.1 \%$ & 0.018 & 3.72 & 1.26 & 11.04 \\
\hline 11 & $17.4 \%$ & 0.148 & 2.15 & 0.76 & 6.03 \\
\hline 12 & $20.0 \%$ & 0.066 & 2.55 & 0.94 & 6.93 \\
\hline 13 & $15.6 \%$ & 0.220 & 1.86 & 0.69 & 5.02 \\
\hline 14 & $9.8 \%$ & & 1 (ref) & & \\
\hline \multicolumn{6}{|c|}{ Weight percentile group } \\
\hline 25 and below & $11.0 \%$ & 0.027 & 0.37 & 0.15 & 0.89 \\
\hline$>25$ to $<75$ & $18.9 \%$ & 0.375 & 0.71 & 0.33 & 1.52 \\
\hline 75 and above & $25.7 \%$ & & 1 (ref) & & \\
\hline
\end{tabular}

bound, bold values indicate statistically significant values.

\subsection{Potential Factors Associated with Overuse Injuries}

None of the factors tested on association with overuse injuries was significant (Table 4). Statistical trends were found for maturity group, puberty status, and height percentile group, $p<0.10$, where a non-significantly higher injury risk was found for athletes being early maturing, post-pubertal, and larger.

Table 4. Potential factors associated with overuse injuries according to the simple general estimating equation analysis ( $n=482$ observations).

\begin{tabular}{|c|c|c|c|c|c|c|c|}
\hline Variable & $\begin{array}{l}\% \text { Observations } \\
\text { with Injuries }\end{array}$ & $\begin{array}{l}\text { N Observations } \\
\text { with Injuries }\end{array}$ & N Observations & $p$ & $\mathrm{OR}^{1}$ & $95 \% \mathrm{CI} \mathrm{lb}^{2}$ & $95 \%$ CI ub ${ }^{3}$ \\
\hline \multicolumn{8}{|l|}{ Sex } \\
\hline Female & $7.3 \%$ & 14 & 191 & 0.952 & 0.97 & 0.42 & 2.28 \\
\hline Male & $7.6 \%$ & 22 & 291 & & 1 (ref) & & \\
\hline \multicolumn{8}{|c|}{ Relative age quarter } \\
\hline 1st & $7.2 \%$ & 11 & 153 & 0.875 & 0.91 & 0.30 & 2.82 \\
\hline 2nd & $7.4 \%$ & 11 & 149 & 0.956 & 0.97 & 0.28 & 3.30 \\
\hline $3 \mathrm{rd}$ & $7.7 \%$ & 8 & 104 & 0.998 & 1.00 & 0.30 & 3.27 \\
\hline 4th & $7.9 \%$ & 6 & 76 & & 1 (ref) & & \\
\hline \multicolumn{8}{|l|}{ Age } \\
\hline 10 & $8.8 \%$ & 5 & 57 & 0.600 & 1.50 & 0.33 & 6.82 \\
\hline 11 & $3.7 \%$ & 4 & 109 & 0.391 & 0.55 & 0.14 & 2.14 \\
\hline 12 & $5.4 \%$ & 7 & 130 & 0.865 & 0.88 & 0.20 & 3.79 \\
\hline 13 & $12.6 \%$ & 17 & 135 & 0.199 & 2.12 & 0.67 & 6.66 \\
\hline 14 & $5.9 \%$ & 3 & 51 & & 1 (ref) & & \\
\hline \multicolumn{8}{|l|}{$\begin{array}{l}\text { Maturity } \\
\text { group } 4\end{array}$} \\
\hline Early & $15.8 \%$ & 12 & 76 & 0.091 & 2.61 & 0.86 & 7.93 \\
\hline Average & $5.8 \%$ & 19 & 330 & 0.757 & 0.84 & 0.28 & 2.55 \\
\hline Late & $6.6 \%$ & 5 & 76 & & 1 (ref) & & \\
\hline \multicolumn{8}{|l|}{$\begin{array}{l}\text { Puberty } \\
\text { status } 5\end{array}$} \\
\hline Pre-pubertal & $4.5 \%$ & 8 & 179 & 0.069 & 0.37 & 0.12 & 1.08 \\
\hline Pubertal & $8.6 \%$ & 19 & 222 & 0.449 & 0.71 & 0.29 & 1.72 \\
\hline Post-pubertal & $11.1 \%$ & 9 & 81 & & 1 (ref) & & \\
\hline \multicolumn{8}{|c|}{ Core flexion to extension strength ratio group 6} \\
\hline $\begin{array}{c}\text { Ratio } 1 \\
\text { and below }\end{array}$ & $8.1 \%$ & 19 & 236 & 0.274 & 1.45 & 0.75 & 2.81 \\
\hline Ratio $>1$ & $7.1 \%$ & 15 & 210 & & 1 (ref) & & \\
\hline
\end{tabular}


Table 4. Cont.

\begin{tabular}{|c|c|c|c|c|c|c|c|}
\hline Variable & $\begin{array}{l}\% \text { Observations } \\
\text { with Injuries }\end{array}$ & $\begin{array}{l}\text { N Observations } \\
\text { with Injuries }\end{array}$ & N Observations & $p$ & $\mathrm{OR}^{1}$ & $95 \% \mathrm{CI} \mathrm{lb}^{2}$ & $95 \% \mathrm{CI} \mathrm{ub}$ \\
\hline \multicolumn{8}{|c|}{ Height percentile group ${ }^{7}$} \\
\hline $\begin{array}{l}25 \text { and } \\
\text { below }\end{array}$ & $6.9 \%$ & 8 & 116 & 0.110 & 0.43 & 0.15 & 1.21 \\
\hline$>25$ to $<75$ & $6.4 \%$ & 19 & 295 & 0.088 & 0.44 & 0.17 & 1.13 \\
\hline $\begin{array}{l}75 \text { and } \\
\text { above }\end{array}$ & $14.1 \%$ & 9 & 64 & & 1 (ref) & & \\
\hline \multicolumn{8}{|c|}{ Weight percentile group 8} \\
\hline $\begin{array}{l}25 \text { and } \\
\text { below }\end{array}$ & $4.2 \%$ & 5 & 118 & 0.140 & 0.39 & 0.11 & 1.36 \\
\hline$>25$ to $<75$ & $8.0 \%$ & 23 & 286 & 0.616 & 0.77 & 0.27 & 2.16 \\
\hline $\begin{array}{l}75 \text { and } \\
\text { above }\end{array}$ & $11.4 \%$ & 8 & 70 & & 1 (ref) & & \\
\hline
\end{tabular}

${ }^{1}$ OR: odds ratio, ${ }^{2}$ 95\%CI lb: 95\% confidence interval lower bound, ${ }^{3} 95 \% \mathrm{CI}$ ub: $95 \%$ confidence interval upper bound, ${ }^{4}$ groups according to age at peak height velocity, ${ }^{5}$ according to distance to age at peak height velocity, ${ }^{6}$ missing observations $=36,{ }^{7}$ missing observations $=7,{ }^{8}$ missing observations $=8$.

\section{Discussion}

\subsection{Incidence of Traumatic and Overuse Injuries}

In total, 104 traumatic injuries occurred during the four-year period (63.9\% reported by males); 45 separate athletes ( $62.5 \%$ of all athletes) were affected. An average injury incidence of 0.22 injuries/athlete per season (September until April or April until September) was calculated, which is lower compared to previous studies in youth ski racing (0.46 traumatic injuries/athlete per season) [7]. However, it has to be considered that in the present study, the incidence was calculated for half-year-periods (competitive season and preparation season). Nevertheless, a relatively low incidence of traumatic injuries was found compared with adolescent ski racers (injury risk: 0.67) [5] or elite ski racers at the World Cup level (0.36 injuries/athlete/season) [3]. However, when comparing the competitive seasons (September-April) of the four-year periods (10-14-year-old athletes) with the preparation seasons (April-September), the incidence of traumatic injuries was obviously higher during the competitive season for all age groups. This finding is in line with a study in adolescent ski racing, in which Hildebrandt and Raschner [5] reported higher rates of traumatic injuries during the winter seasons compared with the summer seasons for both males and females.

In total, only 39 overuse injuries were reported during the four-year period (64.1\% reported by males); 25 separate athletes (34.7\% of all athletes) were affected. A very low overuse injury rate of 0.08 injuries/athlete per season (September until April or April until September) was calculated, which is comparable to the rate found in a previous study in youth ski racing $(0.13$ overuse injuries/athlete/season) [7]. In adolescent ski racing ( $>50 \%$ of the athletes during 2-season study period) [5] and elite ski racing ( $>1 / 3$ of the top-40 ranked Slalom athletes) [29], higher rates of overuse injuries were identified. Hildebrandt and Raschner [5] found a higher risk for overuse injuries during the summer season, while a higher risk for traumatic injuries was present during the winter season in adolescent ski racers. In the present study, a lower incidence for traumatic injuries during the preparation season was identified, but the incidence of overuse problems was approximately the same. When looking at descriptive results, a slightly higher incidence of overuse problems was identified in the competitive seasons and preparation season of athletes aged between 12.5 and 13.5 years. However, it only can be speculated that in the older athletes, the training loads are higher, which might lead to more overuse problems the older the athletes are, or overuse problems are developed with time and are therefore, more reported in older athletes, as the study of Hildebrandt and Raschner [5] shows.

\subsection{Severity of Traumatic and Overuse Injuries and Affected Body Parts}

Most traumatic injuries were moderate (41.3\%), which means a time-loss of training of 8-28 days, whereas only $15.4 \%$ were severe (time-loss of $>28$ days). These findings are in line with previous 
studies in youth ski racing ( $44.9 \%$ moderate; $13.1 \%$ severe) and adolescent ski racing (15-19 years; $46 \%$ moderate; $41 \%$ severe) [5], whereas at the World Cup level, most injuries were classified as severe injuries (>36\%) [30]. However, at the World Cup level, injury registration was performed retrospectively, which might lead to the assumption that not all minimal and moderate injuries were reported, as it was done in the present prospective study. With respect to injury location, the present results confirm previous findings in youth ski racing [6], adolescent ski racing [5], and elite ski racing [3]: most traumatic injuries (66.3\%) affected the lower extremities; most of them were located at the knee. Based on these findings, it can be concluded that also in youth ski racing, the knee is the most vulnerable body part by traumatic injuries.

Most overuse injuries were mild (33.3\%), followed by moderate $(30.6 \%)$, minimal $(22.2 \%)$, and only $13.9 \%$ were categorized as severe. Only $15 \%$ of the overuse problems were recurring, which is a finding that is comparable with a previous study in youth ski racing, in which $23.1 \%$ of the reported overuse injuries were recurrent [4]. This finding indicates that the youth athletes had sufficient time to recover, and the pressure to return to training and competition or train despite symptoms was not that high. In line with a previous study in youth ski racing [4], the lower extremities were the most affected body parts also by overuse injuries; in the present study, $82.4 \%$ affected the lower extremities, which is comparable to the $82.3 \%$ affecting the knee in the reported study [4]. Growing athletes suffer from unspecified but self-limiting knee problems; the growth rate of the apophysis is slower than that of the epiphyseal plate, leading to problems of the interface between bone and ligaments; most overuse injuries were classified as typical apophysitis, such as Osgood-Schlatter disease [31]. Based on the present and previous findings, it can be concluded that in young ski racers, overuse problems are more relevant in the lower extremities, whereas the older the athletes are, the more overuse problems in the trunk become more relevant [5].

\subsection{The Role of Chronological and Relative Age in Injury Risk Identification}

Chronological age seems to be a relevant factor in traumatic injury risk identification. A statistically significant higher risk for traumatic injuries was found in 10-year-old athletes $(\mathrm{OR}=3.36)$. The highest rate of injured observations was found during the competitive season after the first investigation of the athletes, when they were in mean $10.6 \pm 0.3$ years old. This finding might be explained by the different preconditions of the young ski racers before frequenting the ski boarding school. After having passed the entrance exam for the school, which normally takes place in the fall, they start with their dual career (school and ski racing) in September (first examination of the athletes in present study). Some athletes had already trained with experienced coaches and were already well-prepared, whereas others did not have any planned training sessions except for participating in ski races; thus, an inhomogeneous group of athletes might start with the first school year. However, all of them have then the same training loads of skiing-specific and athletic-specific training. It might be assumed that these loads are too much for some athletes during the first months in the new school; together with the new life in the boarding school and psychological stress to perform well, it might lead to the high traumatic injury rates in this age group. This result is in line with a study in youth soccer, in which an association between traumatic injuries and chronological (younger) age was found [32]. In this context, in the future, it might be necessary to adapt the training loads based on the diverse preconditions of the pupils when entering the school.

Chronological age might be more relevant in identifying athletes at higher risk for sustaining traumatic injuries than relative age. In line with a previous study in youth ski racing [4], in which no difference in frequencies of traumatic injuries between the four relative age quarters was found, the relative age quarter was not identified to be a significant risk factor in the present study. However, the fourth relative age quarter was considered as a reference in the statistical analyses, which means that the other three quarters were compared with Q4. As it was also assumed by Müller et al. [4], relatively younger athletes, who might be expected to be at a higher injury risk based on previous findings in different sports (a.o., [32]), may have counteracted their relative age disadvantage if they 
were more mature and possibly at a higher level of physical fitness. Thus, they might present the same physical conditions as their relatively older counterparts and therefore, they might not be at a higher injury risk.

\subsection{The Role of Biological Maturity in Injury Risk Identification}

Although not significant in the present dataset, pre-pubertal athletes might be more at risk for traumatic injuries compared to post-pubertal athletes, as at least a tendency was observed. This finding seems plausible, since Kemper et al. [33] showed that anthropometric characteristics such as rapid growth rates and BMI increase seem to identify youth athletes at high injury risk; this seems particularly true between the year before PHV and the year of PHV [9,11]. Additionally, Caine et al. [34] found the adolescent growth spurt to be a time of an increased risk for sports injuries; an association between PHV and peak fracture rate was found. Jayanthi et al. [35] additionally revealed that growth plate tissue may be more vulnerable to injury during periods of rapid growth, which means that athletes are more susceptible to injuries during rapid phases of growth, which might be true for pre-pubertal as well as pubertal athletes but not for post-pubertal athletes. Growth spurts might lead to changes in the ratios of muscle strength to body or limb mass and moments of inertia; soft tissues may sustain increased stress and strain [36]. Individual monitoring of anthropometrics and corresponding growth spurts is necessary to determine an increased risk of injury occurrence [36]. Regular assessments of anthropometric characteristics, e.g., all three months, should be performed in order to be able to consider growth rates in future studies, which is especially important for the age group of athletes prior to or at the beginning of puberty $[37,38]$.

In contrast to traumatic injuries, a tendency was present that post-pubertal athletes might be more prone to overuse injuries. Previous findings in youth ski racing identified lighter athletes at a higher injury risk [6]. Thus, the present results revealing a significant higher injury risk in athletes being in the higher weight percentile group compared to the lower percentile group $(\mathrm{OR}=0.38)$ was surprising and cannot really be explained. It should be noted in this context that unlike previous studies, the present GEE analysis does not exclusively compare heavier versus lighter athletes (due to repeated measurements across athletes). This approach may consider intra-individual fluctuations over the four seasons, e.g., comparing not only between separate athlete groups, but also between different time points, where athletes fall into different weight percentiles.

Previous studies in soccer [11,12] and youth ski racing [6] showed that late maturing athletes were at a higher risk for sustaining traumatic and overuse injuries, whereas in the present study, no significant difference in injury risk for both types of injuries was identified between early, normal, and late maturing athletes. However, in the study of Müller et al. [6], an association was identified only between APHV and injury severity; namely, athletes with lower APHV values, which means that they are earlier maturing, were more likely to miss fewer days of training due to injuries. In the present study, injury severity was not considered in identifying risk factors, which means that minimal, mild, moderate, and severe injuries were included combined. However, the results are in line with those of Müller et al. [6] showing no difference in injury risk in general (injured or not) between different maturity groups. With respect to overuse injuries, the unexpected finding that a tendency was present for early maturing athletes being at a higher risk was found. Even though this result cannot really be explained, as previous studies in soccer showed a higher risk of sustaining overuse injuries for late maturing athletes [11], it leads to the assumption that traumatic and overuse injuries should be considered separately when talking about injury risk among athletes of differing maturity statuses.

\subsection{Gender-Specific Differences in Injury Risk}

Previous findings on the role of sex in injury risk included that female adolescent ski racers (15-19 years) were at a twofold higher risk of sustaining a rupture of the ACL than their male counterparts (relative risk of 2.3) [13]; similar findings were found in older studies for World Cup athletes $[39,40]$. However, other studies in elite ski racers revealed that male athletes were at a higher 
risk for injuries in general and for time-loss injuries than females [29,41]. Spörri et al. [3] concluded that the influence of sex might depend on the type of injury, as females might be at a higher risk for ACL injuries and injuries at the knee in general. In other types of sport, such as basketball and soccer, a fourfold to sixfold higher risk in sustaining an ACL injury was found for females compared to males, independent of the age of the athletes [42,43]. However, in the present study, sex did not play a role in injury risk identification of both traumatic and overuse injuries. This might be explained by the fact that all injuries were considered combined (separated by traumatic and overuse injuries), and specific injuries, such as ACL injuries, were not analyzed separately. In the present sample, only three ACL ruptures occurred; two of them affected female athletes. A slightly higher percentage of males were affected by traumatic injuries $(19.2 \%)$ compared to females $(16.2 \%)$, whereas approximately $7 \%$ of both males and females were affected by overuse injuries. These findings are in line with a previous study in youth ski racing [4], in which no sex-specific differences were found in the occurrence of traumatic injuries; it was hypothesized that this might be associated with similar training-load exposure, as skiing-specific and athletic-specific training sessions were conducted together for males and females [4], which was also the case in the present study. In addition, Raschner et al. [13] argued that during alpine ski racing events, the influence of external factors, such as weather and snow conditions, overrule gender-specific risk factors such as anatomical differences or hormonal influences. It might be hypothesized that anatomical and hormonal differences might be more relevant after puberty.

Thus, it can be concluded that in the age group of 10- to 14-year-old ski racers, sex does not represent a critical factor for sustaining injuries. This might be explained by the fact that in this age group, males and females do not present great differences in physical performance and therefore, they might be similarly prepared for the demands in ski racing. Additionally, in the ski boarding school, males and females participate in the same training sessions together, and therefore, they have the same training loads and contents; they participate in the same races with the same difficulties. Only males and females starting at the FIS age participate in diverse races with different conditions/difficulties.

\subsection{The Role of Core Flexion to Extension Strength Ratio in Injury Risk Identification}

One study in adolescent ski racing revealed core strength imbalances as an ACL injury risk factor in male athletes [13]. Male athletes who sustained an ACL injury showed either much higher mean values (1.10), indicating that their core flexor muscles were too strong, or lower values (0.65), indicating weak trunk extensor muscles [13]. Insufficient core strength, inappropriate recruitment of the core muscles, and imbalances of these muscles might contribute to low back pain (LBP) [44], which represents a severe overuse problem in alpine ski racing in elite athletes [3] and adolescent athletes [5]. Even though LBP is not such a severe overuse problem in youth ski racers, as most of the overuse injuries were located in the lower extremities (82.4\%) and only $17.6 \%$ were located in the trunk in the present study, a well-balanced core strength seems important in an injury prevention context. However, the present results did not reveal a significant association between core strength ratios and injury risk according to the GEE analysis. In this context, the used threshold of the core flexion to extension strength ratio of $>1$ and $\leq 1$ has to be critically considered, as reference values of "good" or "weak" or "high risk" trunk strength ratios of alpine ski racers do not exist in the literature. In the present study, the ratio was defined only as stronger flexors or stronger extensors.

\section{Limitations}

The main limitation of the present study was that despite prospectively monitoring athletes over a period of four years, still, a low number of injuries was reported, especially of overuse injuries. This fact is of course desirable for the athletes and underlines the well-prepared and planned talent development work done in the ski boarding school, but it makes it difficult to have sufficiently powered datasets. Furthermore, it is unclear whether the used coding of diverse variables was appropriate, as for example, the threshold value of the core strength ratios of $>1$ versus 1 and smaller. However, the main strength of the present study was the long period for a prospective study: namely, four years. 
Additionally, the GEE analysis is a relatively new way of identifying risk factors in youth ski racing by combining several seasons and considering the data structure of repeated measurements. A new aspect of the present study was considering traumatic and overuse injuries separately, because potentially different mechanisms and consequently different risk factors are assumed. As some significant risk factors for traumatic injuries were identified (chronological age, weight percentile group; tendency: pubertal status), no significant risk factor was found for overuse injuries. Therefore, future studies including other parameters, such as growth rates, are necessary in order to be able to identify risk factors for overuse injuries as well.

\section{Conclusions}

The present study was the first prospective study investigating possible risk factors for traumatic and overuse injuries in youth alpine ski racers over a longer period (4 years). Anthropometric percentiles, biological maturity status, core flexion to extension strength ratio, as well as sex, relative age, and chronological age were included as possible injury risk factors. With respect to traumatic injuries, only two injury risk factors were identified: age and weight percentile. Puberty status showed a tendency for a higher injury risk for pre-pubertal athletes. The analyses did not reveal a significant risk factor for overuse injuries; maturity group, puberty status and height percentile showed only tendencies in the analysis. Based on these results, it can be concluded that injury prevention programs in youth ski racing should consider chronological age and biological maturity. Additionally, traumatic and overuse injury risk should be considered separately. In future studies, growth rates should be considered in order to consider the impact of growth.

Author Contributions: Conceptualization, L.S.-M., C.H., M.N., E.M., M.R., M.J., B.B. and C.R.; methodology, L.S.-M. and C.H.; formal analysis, M.N. and L.S.-M.; investigation, L.S.-M., C.H. and C.R.; resources, C.R.; data curation, L.S.-M. and C.H.; writing-original draft preparation, L.S.-M., E.M. and M.N.; writing-review and editing, L.S.-M., C.H., M.N., E.M., M.R., M.J., B.B. and C.R.; visualization, M.N. and L.S.-M.; project administration, L.S.-M. All authors have read and agreed to the published version of the manuscript.

Funding: This research received no external funding. The authors want to thank the University of Innsbruck for the funding of the publication.

Acknowledgments: The authors want to thank all pupils and the coaches for participation in this study.

Conflicts of Interest: The authors declare no conflict of interest.

\section{References}

1. Lansdown, D.A.; Rugg, C.M.; Feeley, B.T.; Pandya, N.K. Single Sport Specialization in the Skeletally Immature Athlete: Current Concepts. J. Am. Acad. Orthop. Surg. 2020, 28, e752-e758. [CrossRef]

2. Hildebrandt, C.; Oberhoffer, R.; Raschner, C.; Müller, E.; Fink, C.; Steidl-Müller, L. Training load characteristics and injury and illness risk identification in elite youth ski racing: A prospective study. J. Sport. Health. Sci. 2020. [CrossRef]

3. Spörri, J.; Kröll, J.; Gilgien, M.; Müller, E. How to prevent injuries in alpine ski racing: What do we know and where do we go from here? Sports Med. 2017, 47, 599-614. [CrossRef]

4. Müller, L.; Hildebrandt, C.; Müller, E.; Oberhofer, R.; Raschner, C. Injuries and illnesses in a cohort of elite youth alpine ski racers and the influence of biological maturity status and relative age: A two-season prospective study. Open Access J. Sports Med. 2017, 8, 113-122. [CrossRef]

5. Hildebrandt, C.; Raschner, C. Traumatic and overuse injuries among elite adolescent alpine skiers: A two-year retrospective analysis. Int. Sport Med. J. 2013, 14, 245-255.

6. Müller, L.; Hildebrandt, C.; Müller, E.; Fink, C.; Raschner, C. Long-term athletic development in youth alpine ski racing: The effect of physical fitness, ski racing technique, anthropometrics and biological maturity status on injuries. Front. Physiol. 2017, 8, 656. [CrossRef]

7. Steidl-Müller, L.; Hildebrandt, C.; Müller, E.; Raschner, C. Relationship of Changes in Physical Fitness and Anthropometric Characteristics over One Season, Biological Maturity Status and Injury Risk in Elite Youth Ski Racers: A Prospective Study. Int. J. Environ. Res. Public Health 2020, 17, 364. [CrossRef] 
8. Steidl-Müller, L.; Hildebrandt, C.; Müller, E.; Fink, C.; Raschner, C. Limb symmetry index in competitive alpine ski racers: Reference values and injury risk identification according to performance level. J. Sport Health Sci. 2018, 7, 405-415. [CrossRef]

9. DiFiori, J.P.; Benjamin, H.J.; Brenner, J.S.; Gregory, A.; Jayanthi, N.; Landry, G.L.; Luke, A. Overuse injuries and burnout in youth sports: A position statement from the American medical society for sports medicine. Br. J. Sports Med. 2014, 48, 287-288. [CrossRef]

10. Fort-Vanmeerhaeghe, A.; Romero-Rodriguez, D.; Montalvo, A.M.; Kiefer, A.W.; Lloyd, R.S.; Myer, G.D. Integrative neuromuscular training and injury prevention in youth athletes. Part I: Identifying risk factors. Str. Cond. J. 2016, 38, 36-48. [CrossRef]

11. Van der Sluis, A.; Elferink-Gemser, M.T.; Brink, M.S.; Visscher, C. Importance of peak height velocity timing in terms of injuries in talented soccer players. Int. J. Sports Med. 2015, 36, 327-332. [CrossRef]

12. Le Gall, F.; Carling, C.; Reilly, T. Biological maturity and injury in elite youth football. Scand. J. Med. Sci. Sports 2007, 17, 564-572. [CrossRef]

13. Raschner, C.; Platzer, H.P.; Patterson, C.; Werner, I.; Huber, R.; Hildebrandt, C. The relationship between ACL injuries and physical fitness in young competitive ski racers: A 10-year longitudinal study. Br. J. Sports Med. 2012, 46, 1065-1071. [CrossRef]

14. Braegger, C.; Jenni, O.G.; Konrad, D.; Molinari, L. Neue Wachstumskurven für die Schweiz. Paediatrica 2011, 22, 9-11.

15. Kromeyer-Hauschild, K.; Wabitsch, M.; Kunze, D.; Geller, F.; Geisz, H.C.; Hesse, V.; von Hippel, A.; Jaeger, U.; Johnsen, D.; Korte, W.; et al. Percentiles of body mass index in children and adolescents evaluated from different regional German studies. Monatsschrift Kinderheilkd. 2001, 149, 807-818. [CrossRef]

16. Mirwald, R.L.; Baxter-Jones, A.D.G.; Bailey, D.A.; Beunen, G.P. An assessment of maturity from anthropometric measurements. Med. Sci. Sports Exerc. 2002, 34, 689-694. [CrossRef]

17. Sherar, L.B.; Baxter-Jones, A.D.G.; Faulkner, R.A.; Russell, K.W. Do physical maturity and birth date predict talent in male youth ice hockey players? J. Sports Sci. 2007, 25, 879-886. [CrossRef]

18. Müller, L.; Müller, E.; Hildebrandt, C.; Kapelari, K.; Raschner, C. Die Erhebung des biologischen Entwicklungsstandes für die Talentselektion-Welche Methode eignet sich? Sportverletz. Sportsc. 2015, 29, 56-63. [CrossRef]

19. Faigenbaum, A.D.; Lloyd, D.G.; Oliver, J.L. Essentials of Youth Fitness; Human Kinetics: Champaign, IL, USA, 2020.

20. Lesinski, M.; Schmelcher, A.; Herz, M.; Puta, C.; Gabriel, H.; Arampatzis, A.; Laube, G.; Büsch, D.; Granacher, U. Maturation-, age-, and sex-specific anthropometric and physical fitness percentiles of German elite young athletes. PLOS ONE 2020, 15, e0237423. [CrossRef]

21. Raschner, C.; Müller, L.; Patterson, C.; Platzer, H.P.; Ebenbichler, C.; Luchner, R.; Lembert, S.; Hildebrandt, C. Current performance testing trends in junior and elite Austrian alpine ski, snowboard and ski cross racers. Sport Orthop. Sport Traumatol. 2013, 29, 193-202. [CrossRef]

22. Platzer, H.P.; Raschner, C.; Patterson, C. Performance-determining physiological factors in the luge start. J. Sports Sci. 2009, 27, 221-226. [CrossRef] [PubMed]

23. Brooks, J.H.; Fuller, C.W. The influence of methodological issues on the results and conclusions from epidemiological studies of sports injuries: Illustrative examples. Sports Med. 2006, 36, 459-472. [CrossRef]

24. Junge, A.; Engebretsen, L.; Alonso, J.M.; Renström, P.; Mountjoy, M.; Aubry, M.; Dvorak, J. Injury surveillance in multi-sport events: The International Olympic Committee approach. Br. J. Sports Med. 2008, 42, 413-421. [CrossRef]

25. Fuller, C.W.; Ekstrand, J.; Junge, A.; Andersen, T.E.; Bahr, R.; Dvorak, J.; Hägglund, M.; Mc Crory, P.; Meeuwisse, W.H. Consensus statement on injury definitions and data collection procedures in studies of football (soccer) injuries. Clin. J. Sport Med. 2006, 16, 97-106. [CrossRef]

26. Clarsen, B.; Myklebust, G.; Bahr, R. Development and validation of a new method for the registration of overuse injuries in sports injury epidemiology. Br. J. Sports Med. 2013, 47, 495-502. [CrossRef]

27. Clarsen, B.; Bahr, R.; Heymans, M.W.; Engedahl, M.; Midtsundstad, G.; Rosenlund, L.; Thorsen, G.; Myklebust, G. The prevalence and impact of overuse injuries in five Norwegian sports: Application of a new surveillance method. Scand. J. Med. Sci. Sports 2015, 25, 323-330. [CrossRef]

28. Pan, W. Akaike's information criterion in generalized estimating equations. Biometrics 2001, 57, 120-125. [CrossRef] 
29. Jahnel, R.; Spörri, J.; Kröll, J.; Müller, E. Prevalence of overuse problems in World Cup alpine skiers—An explorative approach. In 6th International Congress on Science and Skiing_Book of Abstracts; Müller, E., Kröll, J., Lindinger, S., Pfusterschmied, J., Stöggl, T., Eds.; Department of Sport Science and Kinesiology, University of Salzburg: Salzburg, Austria, 2013; p. 143.

30. Bere, T.; Florenes, T.W.; Nordsletten, L.; Bahr, R. Sex differences in the risk of injury in World Cup alpine skiers: A 6-year cohort study. Br. J. Sports Med. 2013, 48, 36-40. [CrossRef]

31. Caine, D.; DiFiori, J.; Maffulli, N. Physeal injuries in children's and youth sport: Reason for concerns? Br. J. Sports Med. 2006, 40, 749-760. [CrossRef]

32. Rommers, N.; Rössler, R.; Goossens, L.; Vaeyens, R.; Lenoir, M.; Witvrouw, E.; D'Hondt, E. Risk of acute and overuse injuries in youth elite soccer players: Body size and growth matters. J. Sci. Med. Sport 2020, 23, 246-251. [CrossRef]

33. Kemper, G.L.J.; van der Sluis, A.; Brink, M.S.; Visscher, C.; Frencken, W.G.P.; Elferink-Gemser, M.T. Anthropometric Injury Risk Factors in Elite-standard youth soccer. Int. J. Sports Med. 2015, 36, 1112-1117. [CrossRef]

34. Caine, D.; Purcell, L.; Maffulli, N. The child and adolescent athlete: A review of three potentially serious injuries. Sports Sci. Med. Rehabil. 2014, 6, 22. [CrossRef]

35. Jayanthi, N.A.; LaBella, C.R.; Fischer, D.; Pasulka, J.; Dugas, L.R. Sports-specialized intensive training and the risk of injury in young athletes. Am. J. Sports Med. 2015, 43, 794-801. [CrossRef]

36. Hawkins, D.; Metheny, J. Overuse injuries in youth sports: Biomechanical considerations. Med. Sci. Sports Exerc. 2001, 33, 1701-1707. [CrossRef]

37. Baxter-Jones, A.D.G.; Thompson, A.M.; Malina, R.M. Growth and Maturation in Elite Young Female Athletes. Sports Med. Arthrosc. Rev. 2002, 10, 42-49. [CrossRef]

38. Balyi, I.; Way, R.; Collin, R. Long-Term Athlete Development, 1st ed.; Human Kinetics Publishers: Champaign, IL, USA, 2013; p. 199.

39. Stevenson, H.; Webster, J.; Johnson, R.; Beynnon, B. Gender differences in knee injury epidemiology among competitive alpine ski racers. Iowa Orthop. J. 1998, 18, 64-66. [PubMed]

40. Eckeland, A.; Dimmen, S.; Lystad, H.; Aune, A.K. Completion rates and injury in alpine races during the 1994 Olympic Winter Games. Scand. J. Med. Sci. Sports 1996, 6, 287-290. [CrossRef]

41. Flørenes, T.W.; Bere, T.; Nordsletten, L.; Heir, S.; Bahr, R. Injuries among male and female World Cup alpine skiers. Br. J. Sports Med. 2009, 43, 973-978. [CrossRef]

42. Agel, J.; Arendt, E.; Bershadsky, B. Anterior cruciate ligament injury in national collegiate athletic association basketball and soccer: A 13-year review. Am. J. Sports Med. 2005, 33, 524-530. [CrossRef]

43. Renstrom, P.; Ljungqvist, A.; A Arendt, E.; Beynnon, B.D.; Fukubayashi, T.; E Garrett, W.; Georgoulis, T.; E Hewett, T.; Johnson, R.P.; Krosshaug, T.; et al. Non-contact ACL injuries in female athletes: An International Olympic Committee current concepts statement. Br. J. Sports Med. 2008, 42, 394-412. [CrossRef]

44. Bergstrøm, K.A.; Brandseth, K.; Fretheim, S.; Tvilde, K.; Ekeland, A. Back injuries and pain in adolescents attending a ski high school. Knee Surg. Sports Traumatol. Arthrosc. 2004, 12, 80-85. [CrossRef] [PubMed]

Publisher's Note: MDPI stays neutral with regard to jurisdictional claims in published maps and institutional affiliations.

(C) 2020 by the authors. Licensee MDPI, Basel, Switzerland. This article is an open access article distributed under the terms and conditions of the Creative Commons Attribution (CC BY) license (http://creativecommons.org/licenses/by/4.0/). 